\title{
GREEN CUTTING FLUID SELECTION USING MOOSRA METHOD
}

\author{
Jagadish $^{1}$, Amitava Ray ${ }^{2}$ \\ ${ }^{1}$ Assistant Professor, Department of Mechanical Engineering, NIT Silchar, Assam, India \\ ${ }^{2}$ Assistant Professor, Department of Mechanical Engineering, NIT Silchar, Assam, India
}

\begin{abstract}
In every manufacturing process, cutting fluid is the key source of environmental pollution, with most favourable selection of cutting fluid for the green manufacturing $(G M)$ being an essential for reducing the environmental pollution. The objective factors considered for the traditional selection are of two: $\operatorname{cost}(C)$ and quality $(Q)$ but green factors also to be considered from the GM point of view. The aim of this research is to select the finest cutting fluid that minimize the environmental impact $(E)$, cost $(C)$ and maximize the quality $(Q)$. This paper presents a new method, namely, multi-objective optimisation on the basis of simple ratio analysis (MOOSRA). A case study of cutting fluid selection for gear hobbing process was presented to validate the proposed model. The obtained result using MOOSRA has been compared with Analytical Hierarchical Process (AHP) and Decision Making Framework (DMF). The result shows that Syntilo 9930c is optimal in comparison with other.
\end{abstract}

Keywords: Green manufacturing (GM), MOOSRA, Green cutting fluid, AHP, MCDM.

\section{INTRODUCTION}

Present scenario the environmental issues are very important in all the manufacturing industries because it creates the serious problem during the manufacturing process. After the ISO900 quality management system standards, the ISO 1400 environmental management system standards and the OHSAS18001 occupational health and safety assessment series published for entire manufacturing industries because cutting fluid used during the manufacturing process itself is main contributor for source of health and environmental risks. Therefore, how to minimize the environmental issues of the manufacturing industry becomes an important focus for the entire manufacturer. Due to this present condition, an advanced manufacturing system need to be done to reduces the environmental factors -green manufacturing (GM) is presented [1-3].

Even in the machining process, cutting fluids are generally used as a coolant to ensure a smooth machining operation, but in actual practice cutting fluid is major source of environmental pollution. Several researcher developed many techniques for cutting fluid selection considering the green aspects such as comprehensive model on cutting fluid mist information in machining, including mechanism of atomization, vaporization and liquefaction method was proposed in [4]. Manufacturing modelling for environmentally impact assessment [5], Explored the overview of environmentally conscious machining [6], Discuss on environmental planning for machining process [7-8], Cutting fluids evaluation based on occupational health and environmental hazards [9], Selection of cutting fluids in machining processes [10], Characterised the ecological factors of cutting fluids and showed its impact on nature, and wild life
[11], Framed a decision making frame work model for green manufacturing [12]. Tuhin. et al [13] employed AHP model for selection of cutting fluid for green manufacturing and compare the result with decision making frame work model.

From the above survey, selection of cutting fluid task found to be a multi criteria decision (MCDM) problem. Hence, a need of proper MCDM method to achieve GM. Many researchers have developed many techniques for solving the MCDM problem such as LINMAP(Linear Programming Techniques for Multidimensional Analysis of Preference[14], Analytic Hierarchic Process (AHP)[15], ELECTRE (Elimination and Choice Translating Reality[16], Technique for Order Preference by Simulation of Ideal Solution (TOPSIS) [17], VIKOR [18], MOORA (Multi-Objective Optimization on basis of Ratio Analysis) is the process of simultaneously optimizing two or more conflicting criteria subject to certain constraints. This method can used in any of the filed like product design selection, facility layout selection, process selection, personal selection, decision on salvage of resources etc and this method works on the principles of multi objective optimization problems This method considers both beneficial and non-beneficial criteria for ranking one or more alternatives from a set of available options. The detailed explanation of MOORA illustrated in literature [19].

From the literature review it reveals that, even though the past researchers have applied various MCDM methods to solve several selection problems, it is observed that none of the author found in the area of cutting fluid selection for green manufacturing. It is also observed that, all these above methods are complex in nature, quite difficult to understand and require extensive mathematical knowledge to implement. Thus, a systematic and efficient approach to cutting fluid 
selection is necessary in order to select the best alternative for a given application, this not only minimizing the environmental factors also improve the efficiency of the selection process.

In this paper, the applications of MOOSRA methods are illustrated. To some extent MOOSRA method is parallel to MOORA method but it is more robust compare to MOORA. The detailed descriptions of MOORA method has been explored in literature [20]. However the basic assumptions of the MOORA method [21] hold good for MOOSRA method also. The definite rewards of MOORA method is (like-less computational time, very simple and stable, minimum mathematical calculations involved, etc.) over other MCDM methods are also available with MOOSRA method. Compare to MOORA, this method has two unique advantages:

1. Negative performance score that may appear in MOORA never appears in this method

2. This method is less sensitive to large variation in the rationalised values of the attributes.

The following sections are organized as follows: section: 2 detailed explanation methods used for this case study. Validation of the proposed theory with a case study discussed in section: 3, section: 4 discuss the results and discussion. Final conclusion and, references have been listed at last section

\section{MOOSRA}

First MOOSRA method has been developed by Das et al. [21]. Generally, the MOOSRA methodology starts with the formulation of decision matrix which has in general four parameters, namely: alternatives, criteria or attributes, individual weights or significance coefficients of each criteria and measure of performance of alternatives with respect to the criteria. The detail explanation of MOOSRA explained below.

\subsection{Step I: Formation of the Decision Matrix}

This methodology starts with the definition of decision matrix in which number of criteria's and alternatives are listed. The performance of each alternative with respect to each critiea is carried out using following equation.

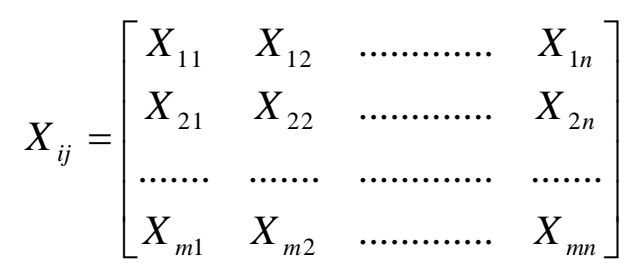

Where, the criteria's are denoted by, $X_{1}, X_{2}, \ldots . X_{n}$.

\subsection{Step II: Normalization of the Fuzzy Decision}

\section{Matrix}

The process of transforming attributes value into a range of 0 1 is called normalization and it is required in multi attribute decision- making methods to transform performance rating with different data measurement unit in a decision matrix into a compatible unit. In MOOSRA method normalized elements of the fuzzy decision matrix using following equation.

$$
X_{i j}^{*}=\frac{X_{i j}}{\sqrt{\sum_{i=1}^{n} X_{i j}^{2}}}
$$

Where, the value $X_{i j}^{*}$ represents the normalized performance of $i^{\text {th }}$ alternative on $j^{\text {th }}$ objective for $i=1,2,3, \ldots . n$ and $j=1,2,3, \ldots . m$.

\subsection{Step III: Determination of Performance of the}

\section{Alternatives}

The performance score $Y_{i}$ of all the alternatives are computed as the simple ratio of weighted sum of beneficial criteria to the weighted sum of non-beneficial criteria using following equation.

$$
Y_{i}=\frac{\sum_{j=1}^{g} w_{j} X_{i j}^{*}}{\sum_{j=g+1}^{n} w_{j} X_{i j}^{*}}
$$

Where, $g$ is the number of attributes to be maximized, $(n-g)$ is the number of attributes to be minimized. $w_{j}$ is an associated weight of the $j^{\text {th }}$ attributes.

In some cases, if we consider that the attributes are equally importance then the optimization formula becomes,

$$
Y_{i}=\frac{\sum_{j=1}^{g} X_{i j}^{*}}{\sum_{j=g+1}^{n} X_{i j}^{*}}
$$




\subsection{Step VI: Ranking of the Alternatives}

In this step, ranking of the alternatives was carried out, When sorted in descending order, the best alternative is that which has the highest assessment value. It is recommended to have an ordinal ranking of $Y_{i}$ values to derive the final preference of the candidate alternatives.

\section{A CASE STUDY}

Based on the above model, a case study is selected to discuss the working and significance of the proposed model. The case study is on the how to select the optimum cutting fluid for a gear hobbing process among three types of cutting fluid in the Chongqing Machine Tool Works, China[12]. The three cutting fluids are, Traditional Cutting fluid (A1), Syntilo 9930c (A2) and Syntilo R Plus cutting oil (A3).

\subsection{Step I: Formation of the Decision Matrix}

In this step, formulation of decision matrix and its relative importance weights has been taken from the published literature [13]. They were shown in Table-3, Table-4. The detailed explanation of calculation procedure has been described in the literature [13].In this study, three main criteria's of GM are quality (Q), environmental impact (E) and $\operatorname{cost}(\mathrm{C})$ are shown in Fig-1, ten sub-criteria's were tabulated in Table-1 and corresponding three alternatives are A1: Traditional Cutting fluid, A2: Syntilo 9930c and A3: Syntilo R Plus cutting oil have been identified has been presented in Table-2.

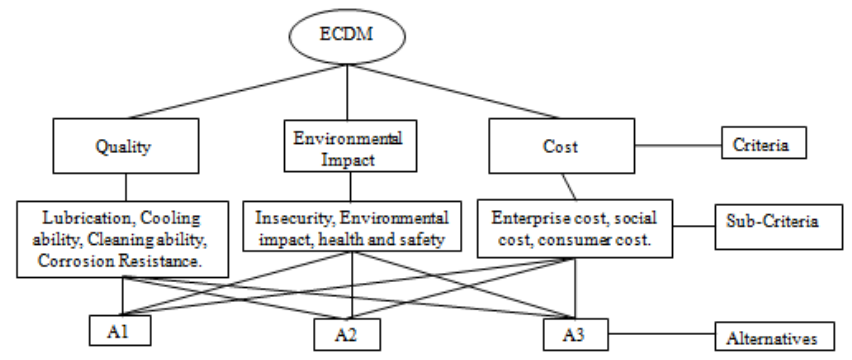

Fig -1: Hierarchy Model for GM [13]

Table-1: List of Criteria [13]

\begin{tabular}{|l|l|}
\hline Criteria \\
\hline Lubricating Ability & C1 \\
\hline Cooling Ability & C2 \\
\hline Cleaning Ability & C3 \\
\hline Corrosion Resistance & C4 \\
\hline Toxicity & C5 \\
\hline Security & C6 \\
\hline Environmental Pollution & C7 \\
\hline Enterprise Cost & C8 \\
\hline
\end{tabular}

\begin{tabular}{|l|l|}
\hline Consumer Cost & C9 \\
\hline social Cost & C10 \\
\hline
\end{tabular}

Table-2: List of Alternative fluids [13]

\begin{tabular}{|l|l|}
\hline \multicolumn{2}{|l|}{ Alternatives } \\
\hline A1 & $\begin{array}{l}\text { Traditional Cutting } \\
\text { fluid }\end{array}$ \\
\hline A2 & Syntilo 9930c \\
\hline A3 & $\begin{array}{l}\text { Syntilo R Plus cutting } \\
\text { oil. }\end{array}$ \\
\hline
\end{tabular}

Table-3: Decision matrix [13]

\begin{tabular}{|l|l|l|l|}
\hline $\begin{array}{l}\text { Alternatives/ } \\
\text { Criteria }\end{array}$ & A1 & A2 & A3 \\
\hline C1 & 0.0923 & 0.6155 & 0.292 \\
\hline C2 & 0.1001 & 0.3 & 0.5997 \\
\hline C3 & 0.1095 & 0.5813 & 0.309 \\
\hline C4 & 0.0926 & 0.615 & 0.2923 \\
\hline C5 & 0.0891 & 0.3234 & 0.5874 \\
\hline C6 & 0.0891 & 0.3234 & 0.5874 \\
\hline C7 & 0.0787 & 0.6584 & 0.2627 \\
\hline C8 & 0.6668 & 0.111 & 0.222 \\
\hline C9 & 0.648 & 0.1221 & 0.2297 \\
\hline C10 & 0.1693 & 0.4433 & 0.3873 \\
\hline
\end{tabular}

Table-4: Criteria Weights [13]

\begin{tabular}{|l|l|}
\hline Criteria & $\begin{array}{l}\text { Weights }(\mathrm{Wj} \\
\text { ) }\end{array}$ \\
\hline C1 & 0.3 \\
\hline C2 & 0.3 \\
\hline C3 & 0.3 \\
\hline C4 & 0.0999 \\
\hline C5 & 0.1221 \\
\hline C6 & 0.2297 \\
\hline C7 & 0.6480 \\
\hline C8 & 0.5813 \\
\hline C 9 & 0.1095 \\
\hline C10 & 0.3090 \\
\hline
\end{tabular}

\subsection{Step II: Normalization of the Decision Matrix}

In this step normalization of the decision matrix using Eqs. (2). corresponding results shown in Table-5.

Table -5: Normalized Decision matrix

\begin{tabular}{|l|l|l|l|}
\hline $\begin{array}{l}\text { Alternatives/ } \\
\text { Criteria }\end{array}$ & A1 & A2 & A3 \\
\hline C1 & 0.1343 & 0.8953 & 0.4247 \\
\hline $\mathrm{C} 2$ & 0.1476 & 0.4425 & 0.8845 \\
\hline
\end{tabular}




\begin{tabular}{|l|l|l|l|}
\hline C3 & 0.1641 & 0.8710 & 0.4630 \\
\hline C4 & 0.1348 & 0.8949 & 0.4254 \\
\hline C5 & 0.1317 & 0.4781 & 0.8684 \\
\hline C6 & 0.1317 & 0.4781 & 0.8684 \\
\hline C7 & 0.1103 & 0.9231 & 0.3683 \\
\hline C8 & 0.9372 & 0.1560 & 0.3120 \\
\hline C9 & 0.9280 & 0.1749 & 0.3290 \\
\hline C10 & 0.2764 & 0.7237 & 0.6323 \\
\hline
\end{tabular}

\subsection{Step III: Determination of Performance of the}

\section{Alternatives}

In this step, computation of preference selection index $y_{i}$ for all he criteria using Eqs. (3). Ranking the alternatives based on preference selection index ${ }^{y_{i}}$.The best alternative is one with highest value of ${ }^{y_{i}}$.The final results were tabulated in Table6.

Table-6: Rank the projects based on assessment value. ${ }^{y_{i}}$

\begin{tabular}{|l|l|l|}
\hline Alternatives & $y_{i}$ & Rank \\
\hline A1 & 0.1718 & 3 \\
\hline A2 & 0.6758 & 1 \\
\hline A3 & 0.5957 & 2 \\
\hline
\end{tabular}

\section{RESULTS AND DISCUSSION}

Optimum selection of cutting fluid for GM point of view helps for the entire manufacturing system to achieve the above mentioned objectives. This research has proposed a new decision making theory to show the effectiveness of the proposed model. The analysis result shows that Syntilo 9930c (SCF2) is optimal in comparison with other and their result has been compared with DMF model and AHP model. The results found to be same is shown in the Fig.2 and Table-7.

Table -7: Result comparison of MOOSRA with other Model.

\begin{tabular}{|l|l|l|l|}
\hline \multirow{2}{*}{ Projects } & \multicolumn{2}{|l|}{ Ranking } & \multicolumn{2}{|l|}{} \\
\cline { 2 - 4 } & MOOSRA & $\begin{array}{l}\text { DMF } \\
\text { Model[12] }\end{array}$ & AHP[13] \\
\hline A1 & 3 & 3 & 3 \\
\hline A2 & 1 & 1 & 1 \\
\hline A3 & 2 & 2 & 2 \\
\hline
\end{tabular}

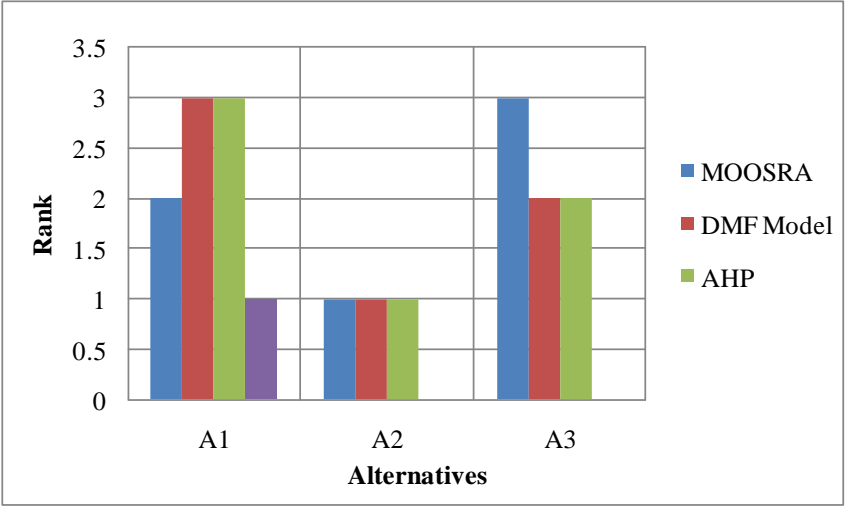

Fig -2: Comparison of results

\section{CONCLUSIONS}

GM is an approach to reduce the environmental impact in the product manufacturing system. Every cutting fluid has different environmental effect during the manufacturing system. The aim of this research to select the optimum cutting fluid that minimizes the environmental impact $(\mathrm{E}), \operatorname{cost}(\mathrm{C})$ and maximizing the quality (Q), for GM. To satisfy this, a new decision making theory is farmed, which integrated the three factors combined in to the cutting fluid for GM. The result is compared with the DMF Model, AHP model and found to be same using proposed methodology

\section{REFERENCES}

[1] R.Zust, Gaduff. 1997. Life cycle modelling as an instrument for life -cycle engineering, Ann.CIRP46, pp-1351-354.

[2] P.Sheng, M.Srinivasan. 1997. Multi-objective process planning in environmental conscious Manufacturing: a feature based approach, Ann.CIRP46, pp-427-433.

[3] ISO 14040. 1997. Environmental management-life cycle assessment - principle and frame work.

[4] Y.Yue. 2000. A comprehensive model for cutting fluid its information in machining, Ph.D thesis, Michgen, Technological University USA.

[5] A.C.K.Choi.1997.Manufacturing modelling for environmentally impact assessment, Journal of Material .Processing Technology .70, pp-231-238.

[6] J.W. Sutherland.1997. An overview of environmentally conscious machining at Michigan Technological University, Presented to the ford motor company, Livonia.

[7] P. Sheng, V. Carey, et.al.1998. Environmental planning for machining operation and system, in proceeding of the 1998 NSF design and manufacturing grantees conference, January 1998.

[8] V. Domkondwar, N. Krishnan, et.al. 1998. Distributed modules in environmental part planning for machined components. CIRP 5th international seminar on life cycle engineering, pp-327-239. 
[9] Julia Meciarova, Miroslav Stanovsky. 2011. Cutting fluids evaluation based on occupational health and environmental hazards, journal of engineering for rural development, Jelgava, 26.-27.05.201, pp-418-422.

[10] O. Cakir, A. Yardimeden, T. Ozben, E. Kilickap. 2007. Selection of cutting fluids in machining processes, 21280 Diyarbakir, Turkey.

[11] M. Sokovic, K. Mijanovic.2001. Ecological aspects of the cutting fluids and its influence on quantifiable parameters of the cutting processes, Journal of Materials Processing Technology, 109(1-2), pp-181189.

[12] X.C. Tan, F. Liu, H.J. Cao, H. Zhang. 2002. A decision-making framework model of cutting fluid selection for green manufacturing and a case study, Journal of materials processing technology. 129, pp 467-470.

[13] Tuhin Deshamukhya and Amitava Ray.2014. Selection of cutting fluid for green manufacturing using analytical hierarchy process (AHP): a case study. Int. Journal Mechanical Engineering and Robotics Research. ISSN 2278 - 0149. Vol. 3(1), pp-174-182.

[14] Srinivasan, V., Shocker, A.D. 1973. Linear programming techniques for multidimensional analysis of privileged. Psychometrika. 38,pp- 337-369

[15] Saaty, T. L. 1980. The analytic hierarchy process. New York: McGraw-Hill.

[16] Roy, B., 1990. Decision-aid and decision-making. European Journal of Operational Research. 45, pp-324331.

[17] Hwang, C. L., Yoon, K. 1981. Multiple attribute decision making, a state of the art survey. New York: Springer-Verlag.

[18] Tong, L. I., Chen, C. C., Wang, C. H. 2007. Optimization of multi-response processes using the VIKOR method. Int. J Adv Manuf. Technol. 31, pp1049-1057.

[19] Brauers, W.K.M., Zavadskas, E.K. 2006.The MOORA method and its application to privatization in a transition economy. Control and Cybernetics. 35 (2), pp- 445-469.

[20] K. Prasad, C. Shankar.2012. Application of multiobjective optimization on the basis of ratio analysis (MOORA) method for materials selection", Materials and Design. 37, pp.317-324.

[21] Das M.C, Sarkar. B, Ray. S. 2012. Decision making under conflicting environment: a new MCDM method. International Journal Applied Decision Sciences. 5, pp142-162.

[22] Jagadish, A. Ray.2014.Cutting fluid selection for sustainable design for manufacturing: an integrated theory, 3rd Int. Conf. on Materials Proces. Charac. (ICMPC 2014), GRIET, Hyderabad, India. (Accepted for Publication).

[23] R. Kumar, Jagadish, A. Ray. 2013. Selection of material: A multi-objective decision making approach.
Presented at the In. Conf. on Ind. Eng., SVNIT, and Surat, India. Proceeding of ICIE-2013 with ISBN: 97893-83083-37-4, pp-162-165.

[24] R. Kumar, Jagadish, A. Ray.2014.Selection of cutting Tool Materials: A holistic approach. Presented at the 1st Int. Conf. on Mech. Eng. Emerging Trends For Sustainability, MANIT, Bhopal, India. (5028), pp- 447452.

[25] R. Kumar, Jagadish, A. Ray.2014. Selection of material for optimal design using multi-criteria decision making, 3rd Int. Conf. on Materials Proces. Charac. (ICMPC 2014), GRIET, Hyderabad, India. (Accepted for Publication). 